\title{
Quiste linfoepitelial intratiroideo: caso clínico y revisión de la literatura
}

\author{
P. SAN MIGUEL FRAILE, G. C. FERNÁNDEZ PÉREZ1', J. A. ORTIZ REY, C. RIVAS \\ BARROS $^{1}$, J. S. ROUCO ROUCO \\ Servicio de Anatomía Patológica, ${ }^{1}$ Radiología, ${ }^{2}$ Cirugía General. Hospital POVISA. Vigo, \\ Pontevedra
}

\begin{abstract}
RESUMEN
Describimos un caso de quiste linfoepitelial intratiroideo en un varón de 31 años con tiroiditis linfocítica crónica y diagnosticado previamente de bocio multinodular. La lesión fue extirpada e histológicamente estaba tapizada por epitelio escamoso y/o cilíndrico y subyacentemente presentaba celularidad linfoide con patrón folicular. Según la literatura revisada, tan sólo hay veinte casos descritos en la literatura médica y en diez casos estaban asociados a tiroiditis crónica.
\end{abstract}

PALABRAS CLAVE: Quiste linfoepitelial. Tiroides. Bocio. Tiroiditis linfocítica.
LYMPHOEPITHELIAL CYST OF THE THYROID GLAND: A CASE REPORT AND REVIEW OF THE LITERATURE

\begin{abstract}
We report a case of lymphoepithelial cyst of the thyroid gland in a 31 year-old-man with chronic lymphocytic thyroiditis and history of multinodular goiter. The lesion was resected and the histopathologic examination showed that the cystic mass was lined by squamous and focally columnar epithelium, an it was surrounded by follicular lymphoid tissue. To our knowledge only twenty cases of this lesion have been reported in the medical literature. An association with chronic thyroiditis has been noted in 10 cases.
\end{abstract}

KEY WORDS: Lymphoepithelial cysts. Thyroid gland. Multinodular goiter. Chronic lymphocytic thyroiditis.

San Miguel Fraile P, Fernández Pérez GC, Ortiz Rey JA, Rivas Barros C, Rouco Rouco JS. Quiste linfoepitelial intratiroideo: caso clínico y revisión de la literatura. An Med Interna (Madrid) 2006; 23: 232-234.

\section{INTRODUCCIÓN}

Los quistes linfoepiteliales intratiroideos son lesiones inusuales histológicamente similares a los quistes branquiales del cuello que se asocian frecuentemente a tiroiditis linfocítica crónica o tiroiditis de Hashimoto (1-5). Histológicamente son lesiones quísticas tapizadas por epitelio plano poliestratificado y a veces focalmente por epitelio respiratorio que muestra subyacentemente un intenso infiltrado inflamatorio linfocitario con patrón folicular.

Describimos un caso de quiste linfoepitelial intratiroideo que se manifestó clínicamente como un bocio multinodular intratorácico y que se asoció a tiroiditis linfocítica crónica. Según la literatura revisada tan sólo hay veinte casos descritos (1-9).

\section{CASO APORTADO}

Varón de 32 años de edad sin antecedentes de interés que presentaba desde hace 4 años, agrandamiento de la glandula tiroides acompañado de síntomas compresivos.

Exploración clínica: bocio multinodular intratorácico con nódulo en lóbulo tiroideo derecho e istmo. No se apeciaban adenopatías laterocervicales.

Pruebas complementarias: analítica general, anticuerpos y hormonas tiroideas dentro de la normalidad.

Se le realizó una ecografía en la que se apreciaron múltiples nódulos en la glándula tiroides que se localizaban sobre todo en el lóbulo tiroideo derecho e istmo. La lesión presentaba áreas quísticas multiseptadas, con calcificaciones groseras en su interior. En el lóbulo tiroideo izquierdo se observaba algún nódulo aislado de pequeño tamaño y con características similares a los anteriormente descritos. El diagnóstico

Trabajo aceptado: 23 de noviembre de 2005

Correspondencia: Pilar San Miguel Fraile. Hospital POVISA. C/ Salamanca, 5. 36211 Vigo (Pontevedra). Fax: 986421 439. e-mail: psanmiguel@ povisa.es 
de la ecografía fue de bocio multinodular. Se le realizó una punción aspiración con aguja fina (PAAF) que se informó como ausencia de células atípicas. Debido a la persistencia de los síntomas compresivos, fundamentalmente disfagia, se le realizó una tiroidectomía total siendo remitida la pieza al servicio de anatomía patológica.

Macroscópicamente se recibió una pieza de tiroidectomía total que medía 8x6x4 cm y pesaba $38 \mathrm{~g}$. A los cortes seriados se observaron múltiples espacios quísticos multiloculados que se localizaban en el lóbulo tiroideo derecho e istmo. La pared era lisa de color rosado y no contenía zonas sólidas. La lesión quística tenía unas dimensiones máximas de $4 \mathrm{~cm}$ y no tenía contenido aparente (Fig. 1). Histológicamente se observaron grandes cavidades quísticas tapizadas por epitelio escamoso o respiratorio sin atipia y subyacentemente mostraba un intenso infiltrado inflamatorio linfocitario con patrón folicular (Fig. 2). En el tejido tiroideo no se apreciaron alteraciones histológicas significativas, excepto un moderado infiltrado inflamatorio linfoide inespecífico.

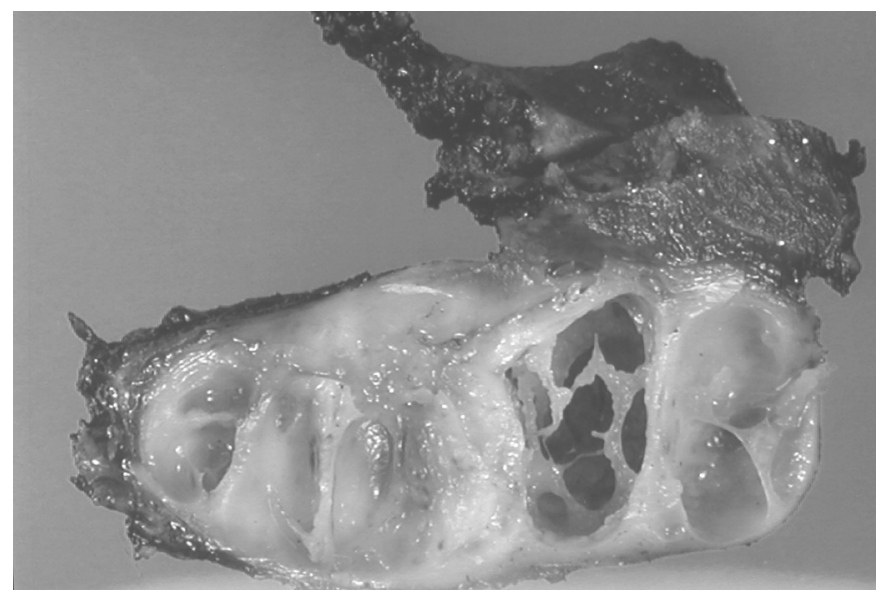

Fig. 1. Características macroscópicas de la lesión quística.

El diagnóstico definitivo del estudio histológico fue de quiste linfoepitelial intratiroideo. El paciente no presentó complicaciones en la cirugía y está sano en el momento actual.

\section{DISCUSIÓN}

Los quistes linfoepiteliales intratiroideos son lesiones inusuales, histológicamente similares a los quistes branquiales del cuello, que han sido descritos en localizaciones muy diversas: cavidad oral (10), glándula parótida (11) y páncreas (12). El primer caso en la glándula tiroides fue descrito por Louis y cols. en 1989 (4) y desde entonces tan sólo se han descrito 20 casos según la literatura revisada (1-9).

La histogénesis de los quistes linfoepiteliales es incierta. Algunos autores, sugieren que el origen de estos quistes podría ser secundario a una respuesta inflamatoria crónica persistente, en donde participaría una respuesta immunitaria celular (1-6). De hecho, es frecuente su asociación a tiroiditis linfocitaria crónica $(1,5,6)$ y tiroiditis de Hashimoto $(2,4)$; sin

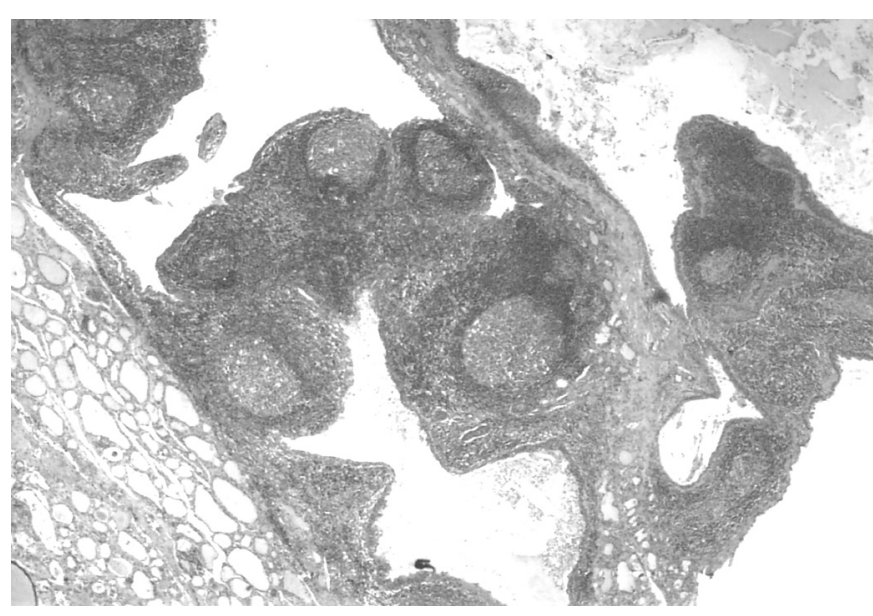

Fig. 2. Quiste linfoepitelial con denso infiltrado inflamatorio linfocitario en su pared (H\&E x 10).

embargo, estos resultados no son concluyentes ya que hay casos descritos en la literatura en donde los quistes linfoepiteliales no se asocian a inflamación en el parénquima tiroideo adyacente. Otra hipótesis, posiblemente la más aceptada, sugiere que se originan en los nidos de células sólidas de la glándula tiroides, las cuales tienen el mismo origen embriológico que las células C o parafoliculares (13). Dato histológico que apoya esta teoría es la presencia de abundantes nidos de células sólidas en la glándula tiroides de estos pacientes que muy frecuentemente se disponen alrededor de los quistes linfoepiteliales (1). En nuestro caso no apreciamos restos de nidos de células sólidas en la glándula tiroides a pesar de haber realizado una búsqueda exhaustiva, pero sí observamos cambios inflamatorios crónicos inespecíficos.

Clínicamente la forma de presentación es variable y no es inusual que sea un hallazgo incidental (1). En este caso el paciente presentaba un agrandamiento difuso de la glándula tiroides y síntomas compresivos. Ecográficamente fue diagnosticado de bocio multinodular intratorácico y se le realizó una tiroidectomía total. De los casos publicados, en siete se realizó tiroidectomía total y en tres de ellos había afectación bilateral (1).

Histológicamente suele ser una lesión quística, multiloculada, tapizada por epitelio escamoso y/o respiratorio y que presenta subyacentemente un intenso infiltrado inflamatorio linfocitario que frecuentemente se dispone formando folículos linfoides. En nuestro caso la histología fue típica (Fig. 2) y presentaba epitelio de revestimiento escamoso y respiratorio, con afectación fundamentalmente de lóbulo derecho e istmo.

En resumen, se trata de una lesión inusual que se manifestó clínica y radiológicamente como un bocio multinodular. Los quistes linfoepiteliales son lesiones quísticas benignas que parecen asociarse a inflamación crónica de la glándula tiroides y que pueden simular bocio o incluso neoplasias tiroideas. 


\section{Bibliografía}

1. Carter E, Ulusarac O, Dyess DL. Lymphoepithelial cysts of the thyroid gland. Arch Pathol Lab Med 2003; 127: 205-208.

2. Asanuma K, Nishio A, Itoh N, Kasuga Y, Amano J. Múltiple branchial cleft-like cysts in a female patient with Hashimoto's thyroiditis. Endocr J 2000; 47 (3): 303-307.

3. Ryska A, Vokurka J, Michal M, etal. Intrathyroidal epithelial cyst: a report of two cases not associated with Hashimito's thyroiditis. Pathol Res Pract 1997; 193: 777-781.

4. Louis DN, Vickery AL Jr, Rosai J, Wang CA. Multiple branchial cleftlike cysts in Hashimoto's thyroiditis. Am J Surg Pathol 1989; 13: 45-49.

5. Haba R, Miki H, Kobayashi S, et al. Intrathyroidal branchial cleft-like cyst in chronic tiroiditis. Pathol Int 2000; 50: 897-900.

6. Apel RL, Asa SL, Chalvardjian A, LiVolsi VA. Intrathyroidal lymphoepithelial cysts of probable branchial origin. Hum Pathol 1994; 25: 1238-1242.

7. Wtanabe I, Kobayashi K, Yamaguchi M, Kasai M. Multinodular lymphoepithelial cyst in the thyroid accompanied with a minute thyroid carcinoma. Pathol Int. 1995; 45: 965-970.
8. Cassarino DS, Milas M, Folpe AL. Bilateral intrathyroidal lymphoepithelial cysts. Arch Pathol Lab Med 2003; 127: 251-252.

9. Simonenko VB, Beliaeu LB, Makanin MA, Dulin PA. Lymphoepithelial cyst of the thyroid. Klin Med (Mok) 2004; 82: 70-71.

10. Epivatianos A, Zaraboukas T, Antoniades D. Coexistence of lymphoepithelial and epidermoid cysts on the floor of the mouth: report of a case. Oral Dis 2005; 11: 330-333.

11. Yen TL, Murr AH, Rabin J, Mhatre AN, Lalwani AK. Role of cytomegalovirus, Epstein-Barr virus, and human herpes virus- 8 in benign lymphoepithelial cysts of the parotid gland. Laryngoscope 2004;114 (8):1500-1505.

12. Shinmura R, Gabata T, Matsui O. Lymphoepithelial cyst of the pancreas: case report with special reference to imaging - pathologic correlation. Abdom Imaging 2006; 31: 106-109.

13. Beckmer ME, Shultz JJ, Richardson T. Solid and cystic ultimobranchial body remnants in the thyroid. Arch Pathol Lab Med 1990; 114: 10491052 . 